\title{
ANALYSIS OF THE KNOWLEDGE THAT STUDENTS OF A UNIVERSITY SUBJECT HAVE REGARDING THE SDGS
}

\author{
Raul Oltra-Badenes, Vicente Guerola-Navarro, Hermenegildo Gil-Gomez \\ Universitat Politècnica de València (SPAIN)
}

\begin{abstract}
On January 1, 2016, the 2030 agenda came into force, and with it, the 17 Sustainable Development Goals (SDG) declared by the UN. These Goals are universally applicable, and will undoubtedly affect our lives directly for years to come, directing the efforts of any organization towards the ultimate goals of ending hunger and poverty, promoting world peace, reducing inequality and fighting for climate change to be able to live on a better planet.

All types of organizations, from the governments of the countries, local administrations or companies, also passing through Universities and other training entities, should be aware of them, and take them into account in their development strategies, since the future of our planet.

But are university students aware of all this? They are the ones who, in the nearest future, must develop and support the strategies and actions necessary to meet these objectives. Without them and their support, it is practically impossible for these goals to be achieved. Therefore, it is essential that university students are aware of the SDGs.

The present work aims to investigate this question, to find out if university students know the SDGs and their content, and are aware of them, seeking to achieve the goals they propose.

To do this, a survey designed for it is transmitted to a group of university students in a final year course. The results obtained are subsequently analyzed. In this way, once the real situation is studied, the degree of knowledge of the students regarding the SDGs can be known, and thus necessary actions can be proposed to raise awareness.
\end{abstract}

Keywords: Sustainable Development Goals, SDG's, Student perception.

\section{INTRODUCTION}

The Sustainable Development Goals (SDGs) are a universal call to action to end poverty, protect the planet, and improve the lives and prospects of people around the world. In 2015, all United Nations Member States approved 17 Goals as part of the 2030 Agenda for Sustainable Development, an initiative that establishes a plan to achieve the Goals established within 15 years.

Those 17 SDGs focus, as their name suggests, on achieving sustainable development, which can be defined as "development capable of meeting the needs of the present without compromising the ability of future generations to meet their own needs" [1]. This sustainable development requires focused efforts to build an inclusive, sustainable and resilient future for people and the planet. According to the UN proposal itself [1] to achieve sustainable development, it is essential to harmonize three basic elements, which are the following: economic growth, social inclusion, and environmental protection. The three elements are interrelated, and are all essential to be able to achieve the well-being of people and societies.

Currently, progress is being made in the development of this SDG initiative in many places, generating and implementing actions, strategies and policies to achieve the 17 SDGs. But overall, action to achieve the Sustainable Development Goals is still not progressing at the necessary speed and scale.

With less than 10 years left to achieve the Sustainable Development Goals, world leaders called for a decade of action and results for sustainable development, vowing to mobilize funding, improve national implementation and strengthen institutions to achieve the Goals on schedule, 2030, leaving no one behind.

The Secretary-General of the United Nations, made a call at the Summit on the SDGs held in September 2019 for all sectors of society to mobilize for a decade of action on three levels: action at the global level to ensure a more leadership, more resources and smarter solutions regarding the Sustainable Development Goals; action at the local level that includes the necessary transitions in policies, budgets, 
institutions and regulatory frameworks of governments, cities and local authorities; and action by people, including youth, civil society, the media, the private sector, trade unions, academia and other stakeholders, to generate an unstoppable movement that drives the necessary transformations. For example, the Government of Spain has actively worked in the elaboration of this universal and transformative agenda [2]

Addressing the challenges of the SDGs will require new knowledge, new ways of doing things, making difficult decisions between competing options and, in some cases, profound transformations.

Of course, this directly involves Universities, as organizations that drive technological and social progress through research, discovery, creation and adoption of knowledge [3]. Universities attract and nurture talent and creativity and are key players in regional and national innovation systems. These roles are critical to helping the global community understand the challenges, opportunities and interactions between the SDGs; develop and implement solutions; develop and evaluate policy options and pathways for transformation; and to track progress. Universities have already begun to implement programs to adapt to this initiative $[4,5]$. But are university students aware of all this? They are the ones who, in the nearest future, must develop and support the strategies and actions necessary to meet these objectives. Without them and their support, it is practically impossible for these goals to be achieved. Therefore, it is essential that university students are aware of the SDGs.

The present work aims to investigate this question, to find out if university students know the SDGs and their content, and are aware of them, seeking to achieve the goals they propose.

To do this, a survey designed for it is transmitted to a group of university students of a subject in a final year course. The results obtained are subsequently analyzed. In this way, once the real situation is studied, the degree of knowledge of the students regarding the SDGs can be known, and thus necessary actions can be proposed to raise awareness.

\section{METHODOLOGY}

To explain the methodology used, first, the subject in which the study was carried out and the context in which it is found will be presented. In this way, you can get an idea of the profile of students who have participated in the study. Subsequently, the designed survey and its main characteristics are presented, to end by commenting on the operation used to pass the survey

\subsection{Contextualization of the subject}

The subject that has been selected to carry out the study is the subject with code 11517, which is called "Integrated Information Systems in Industrial Companies" (SIIEI) and is taught in the Industrial Organization Engineering Degree ( $\mathrm{GIOI}$ ), in the Technical School of Industrial Engineers (ETSI), of the Universidad Politécnica de Valencia (UPV).

This subject is taught in the 4th year, and in the second semester, within the intensification of "Information Systems and Knowledge Management". Therefore, it can be said that the students are in the final stage of the Degree, and after completing the subject, they will be able to complete and present the Final Degree Project, and join the labor market, as Graduates in Industrial Organization Engineering.

For this reason, it is considered that the students of this subject have an ideal profile to measure the degree of knowledge that students have regarding the SDGs at the end of their studies, given that they have already completed practically the entire degree, and have the appropriate maturity in which they should know the initiative and be able to comment on it.

\subsection{Proposal of questionnaire to know the knowledge that the students have about SDG's}

After everything presented in previous sections, the importance of knowing the level of knowledge of the SDGs by university students is evident. Do University students know the SDGs? Do they perceive it as something important? Do they think it is something related to their future and their profession? It seems that it is not like that, but there is no evidence of that.

For this purpose, a survey has been designed in order to be to the students of the SIIEl subject in the UPV. The design of the survey has been done based in different works related, and has been reviewed by different lecturers. 
In the survey there are a total of 12 questions of different types.

The first part of the questionnaire focuses on the student's identifying data. Although it is a completely anonymous survey, questions have been designed to have data and to be able to analyze the responses based on it.

Subsequently, a specific question is proposed in which students indicate to what degree they know the SDGs.

After that, in a third block of the questionnaire they are asked about the importance that they believe the SDGs have for university students. Included here are 5 questions that must be answered based on a Likert scale, in which the 5 options range from "Totally Disagree" to "Totally agree" with the affirmation of each of them, and also an open-ended question

Finally, they are presented with a free text question in which they can include any general comments on the matter.

The survey was developed in Google Forms and was transmitted to the students through a link in one of the classes.

\section{RESULTS}

The survey was answered by a total of 18 students, of the 20 enrolled in the subject.

Regarding the question of knowledge of the SDGs, the answers were the showed in table 1 :

Table 1. Answers to the question: Do you know what the SDGs are?

\begin{tabular}{|l|c|}
\hline \multicolumn{1}{|c|}{ ANSWER } & $N^{\circ}$ \\
\hline No it's the first time I've heard of it & 7 \\
\hline I have heard of the SDGs, but I don't know what they are & 2 \\
\hline Yes, I know what they are, but I don't know what they are & 7 \\
\hline I know perfectly what they are and what they consist of & 2 \\
\hline I have specific training in ODS, I consider myself an expert in the area & 0 \\
\hline
\end{tabular}

Additionally, to check whether or not the students know anything about the SDGs, they were asked how many SDGs they had established, giving them the following options: "12", "21", "17" or "I really don't know". The answers were in accordance with the previous question, being the following: only 2 responses answered "17", most of the responses (12) were to indicate that they did not know, while 3 responses said 12 and one response indicated that the SDGs were 21.

Regarding the 5 questions in which the students expressed their answer based on a Likert scale, the answers have been the following (being 1 Totally disagree and 5 Totally agree)

1 I believe it is important that university students have extensive knowledge about the SDGs and Sustainability in general

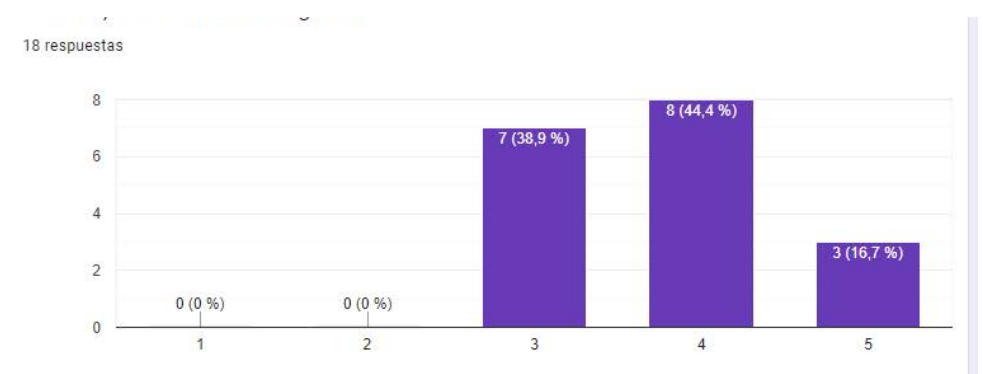

Figure 1. Answers to question "I believe it is important that university students have extensive knowledge about the SDGs and Sustainability in general" 
2 I would like the University to teach how from my (future) profession I could contribute to creating a more sustainable world

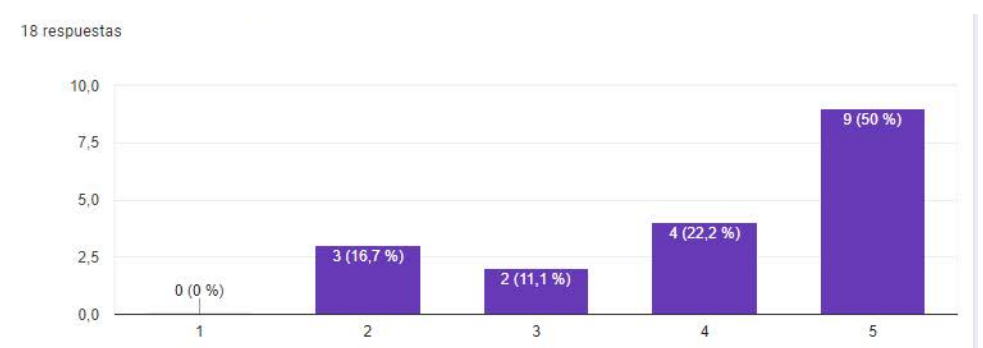

Figure 2. Answers to question "I would like the University to teach how from my (future) profession I could contribute to creating a more sustainable world"

3 I believe that the SDGs, and sustainability in general, should be integrated as part of the themes of university subjects

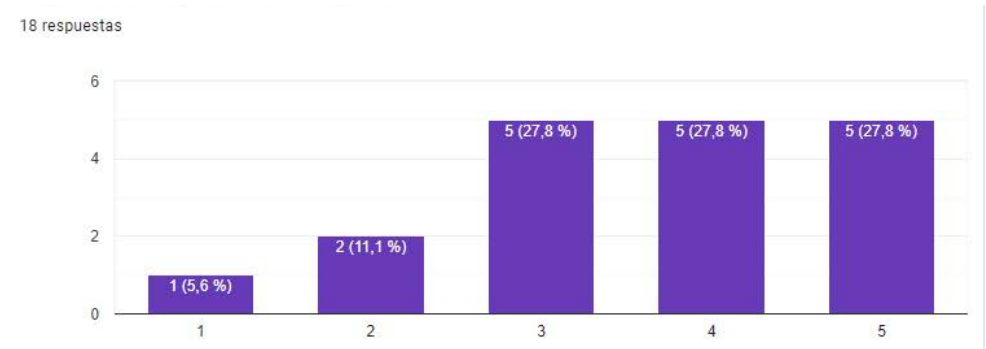

Figure 3. Answers to question "I believe that the SDGs, and sustainability in general, should be integrated as part of the themes of university subjects"

4 I believe that the University should have a comprehensive plan for integrating the SDGs in training, similar to what is done with transversal competences

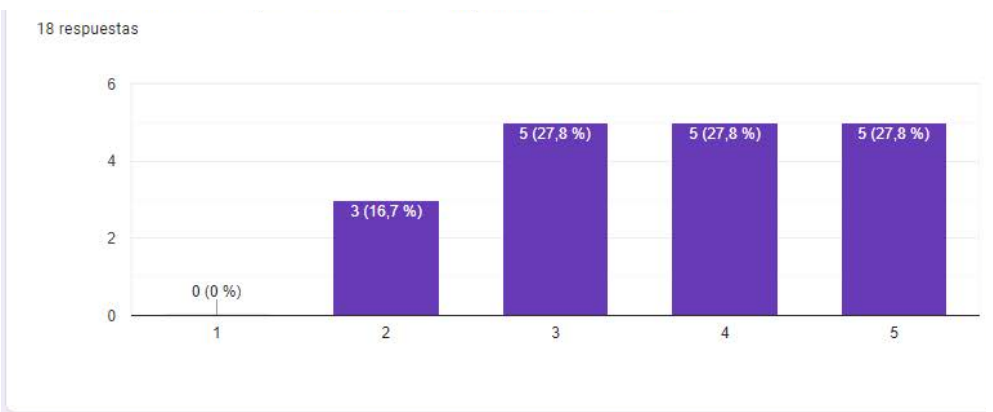

Figure 4. Answers to question "I believe that the University should have a comprehensive plan for integrating the SDGs in training, similar to what is done with transversal competences"

5 I think that at the University we are already taught enough about sustainability issues and the SDGs 


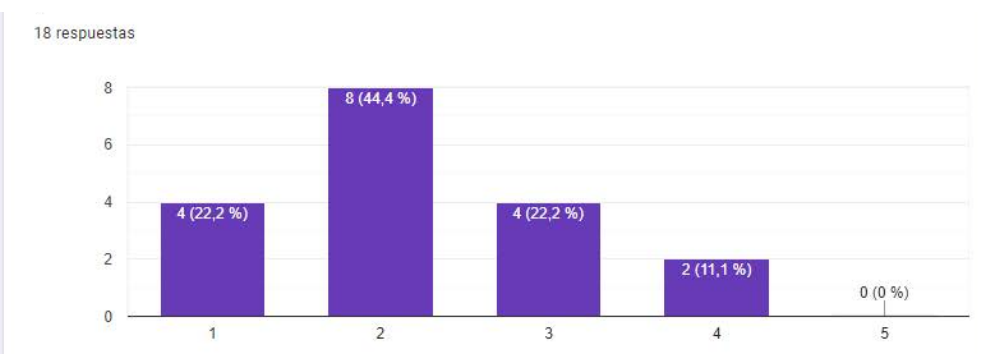

Figure 5. Answers to question "I think that at the University we are already taught enough about sustainability issues and the SDGs"

Regarding the open text question in which they were indicated "Write here any comment that you consider interesting in relation to the SDGs and sustainability", the answers received are the following:

1 Interesting

2 I had never heard of them and that says a lot, but I think it is good for future generations that this topic comes up earlier so that we can raise awareness

3 I don't know them and I think I should

4 I dont know what they are

5 They are very important in order to not have an important moral ethic and not simply be "robots" without feelings or social understanding.

6 I don't know enough

7 It is essential for students to have a sustainable career idea

8 I have no idea what the ODS is

9 It is a topic of interest to be addressed for the goals they seek

10 During the degree we have done specific work on the SDGs, but I think they should be worked on frequently.

11 I think it is more important to make sure that we university students come out well trained in our specialty and prepared to carry out our work in the company, which I do not think is currently the case.

12 I think it is essential to know a minimum about the SDGs. Currently many people are unaware of their existence so they are not given enough importance. They are vital goals and that we should all take into account in our lives.

And for the last question, regarding general comments, the only answer was:

- "Sustainability is important too, but I think there are other things we should focus on improving."

\section{CONCLUSIONS}

As conclusions of the answers obtained, it can be affirmed without a doubt that the students who have responded to the survey are not aware of the SDGs.

In the authors' the opinion, this is an important fact, given that they are final year students, who in two or three months leave the University, and they have not been made aware and trained in Sustainable Development and the SDGs. They will hardly be able to develop their activity contributing to achieving the SDGs, as it should be, if they do not even know what they are and what they consist of.

However, in general, except for a specific case, their attitude in this regard is positive, and they consider it something important and integrated into their studies. This positive attitude is essential and should be used and developed through specific activities.

It must be said that it is a very specific study, with a group of private students, of a single subject with a single degree.

Therefore, after this initial study, and after the results obtained, it seems interesting to repeat this study in other groups and degrees, and thus, to have an image of the real situation, to be able to take the 
appropriate actions and to be able to develop knowledge and Appropriate attitude towards the SDGs in university students

\section{REFERENCES}

[1] United Nations. Sustainable Development Goals. Accessed on date 26/04/2021Retrieved from URL https://www.un.org/sustainabledevelopment/.

[2] Ministerio de Asuntos Exteriores, Unión Europea y Cooperación. Government of Spain. has actively worked in the elaboration of this universal and transformative. Accessed on date. Retrieved from URL

26/04/2021agendahttp://www.exteriores.gob.es/portal/es/politicaexteriorcooperacion/nacionesunid as/paginas/objetivosdedesarrollodelmilenio.aspx.

[3] Tahl Kestin et al., "Cómo empezar con los ODS en las Universidades. Una guía para las Universidades, los centros de educación superior y el sector académico. Red Española para el Desarrollo Sostenible 2018

[4] V. Guerola-Navarro, R. Oltra-Badenes, H. Gil-Gómez "Application of the Atomic bunker game in the development of the SDG "Coordination mechanisms for including gender perspectives" in the subject of "Organizational behavior and change management". International Technology, Education and Development Conference (INTED 2021). (1782 - 1787). Online: IATED. 2021

[5] V. Guerola-Navarro, R. Oltra-Badenes, H. Gil-Gómez "Application of the game on international markets in the development of the Sustainable Development Goal (SDG) of "Reduce inequality between countries" in the university course of "Enterprise ". International Technology, Education and Development Conference (INTED 2021). (1782 - 1787). Online: IATED. 2021 